\title{
BMJ Global Health Hypothesis to explain the severe form of COVID-19 in Northern Italy
}

\author{
Luca Cegolon (10 , ${ }^{1,2}$ Jennifer Pichierri, ${ }^{3}$ Giuseppe Mastrangelo, ${ }^{4}$ Sandro Cinquetti, ${ }^{1}$ \\ Giovanni Sotgiu, ${ }^{5}$ Saverio Bellizzi, ${ }^{6}$ Giuseppe Pichierri ${ }^{7}$
}

To cite: Cegolon L, Pichierri J, Mastrangelo G, et al. Hypothesis to explain the severe form of COVID-19 in Northern Italy. BMJ Global Health 2020;5:e002564. doi:10.1136/ bmjgh-2020-002564

\section{Handling editor Seye Abimbola}

Received 1 April 2020

Revised 11 May 2020

Accepted 13 May 2020

Check for updates

(C) Author(s) (or their employer(s)) 2020. Re-use permitted under CC BY-NC. No commercial re-use. See rights and permissions. Published by BMJ.

${ }^{1}$ Public Health Department, Local Health Unit N. 2 "Marca Trevigiana", Treviso, Veneto Region, Italy

${ }^{2}$ IRCCS Materno Infantile Burlo Garofolo, Trieste, Friuli-Venezia Giulia Region, Italy

${ }^{3}$ Children and Young People's Diabetes, University College London Hospitals NHS Foundation Trust, London, UK ${ }^{4}$ Cardiac, Thoracic and Vascular Sciences, Padua University Hospital, Padua, Veneto Region, Italy

${ }^{5}$ Department of Medical, Surgical and Experimental Sciences, University of Sassari, Sassari, Sardinia Region, Italy ${ }^{6}$ Partnership for Maternal, Newborn and Child Health, World Health Organization, Geneve, Switzerland ${ }^{7}$ Microbiology Department, Kingston Hospital NHS

Foundation Trust, Kingston upon Thames, UK

Correspondence to

Dr Luca Cegolon;

I.cegolon@gmail.com
The ongoing COVID-19 pandemic, caused by the novel severe acute respiratory syndrome coronavirus type 2 (SARS-CoV-2), has affected 212 countries worldwide at various degrees as of 8 May $2020 .{ }^{1}$

In this paper we discuss a hypothesis that prior viral infections-either by SARS-CoV-2 or different strains of coronaviruses, or potentially even other respiratory viruses-may predispose to more severe forms of COVID19, following a secondary infection with SARS-CoV-2.

Most COVID-19 infections are asymptomatic or manifest with mild to moderate respiratory symptoms (fever, cough, sore throat, myalgia, fatigue and even non-severe pneumonia). Of patients with COVID-19, 14\%-15\% develop severe pneumonia and $5 \%-6 \%$ a critical condition requiring admission to intensive care unit (ICU)..$^{2-4}$ Death may eventually occur after an average of 17.8 days since the onset of symptoms. ${ }^{5}$

Among all countries, Italy (which was the first European COVID-19 cluster) presents a critical disease pattern as of 8 May 2020, having the third highest number of COVID-19 cases in the world after the USA and Spain, the fourth highest prevalence of the disease after Spain, Belgium and the USA, the third highest total number of deaths attributed to COVID-19 after the USA and the UK, and the third highest prevalence of COVID-19 mortality after Belgium and Spain, despite a current $1 \%$ rate of severe/critical disease among active cases, which has been progressively decreasing over time. ${ }^{1}$

The cross-country discrepancies in the burden of COVID-19 observed so far across the globe cannot be explained only by differences in population age structures. ${ }^{6-8}$ In fact, Japan has a population double that of Italy, with the proportion of subjects older than 65 being $28.8 \%$ in Japan vs $21.7 \%$ in Italy. ${ }^{9}{ }^{10}$ Nonetheless, as of 8 May 2020, the difference in COVID-19 prevalence between
Summary box

What is already known about this subject?

- Human coronaviruses are known to cause respiratory re-infections, regardless of pre-existing humoural immunity.

- There is evidence suggesting that severe acute respiratory syndrome coronavirus type 2 (SARSCoV-2) had been circulating in Italy before the first COVID-19 case was detected in the country.

\section{What are the new findings?}

- Prior infections with SARS-CoV-2 (or other viruses/ coronaviruses) may arguably predispose to more severe forms of the disease following re-infection with SARS-CoV-2, with an immunological mechanism known as Antibody-Dependent-Enhancement, already observed with infections sustained by other coronaviruses (MERS-CoV and SARS-CoV) or other viruses such as the West Nile Virus and Dengue.

What are the recommendations for policy and practice?

- If confirmed by in vivo studies, this hypothesis may have relevant implications for the treatment of severe forms of COVID-19, yet the possibility to produce an effective vaccine against SARS-CoV-2 might be hampered.

Japan (122 per million) and Italy (3570 per million) is massive. ${ }^{1}$ Likewise, in Germany the percentage of individuals $>65$ is reportedly $22.1 \%$ (hence slightly higher than Italy), but the prevalence of COVID-19 is currently 2022 per million. ${ }^{111}$ In Iran the proportion of people $>65$ is $5.5 \%$ (hence much younger than the Italian, German and Japanese populations), but the prevalence of COVID-19 is 1246 per million, as of 8 May 2020. ${ }^{12}$

The mortality rate for COVID-19 is reportedly enhanced by $5.6 \%-10.5 \%$ in the presence of any comorbidities (hypertension, diabetes, cardiovascular diseases, cancer and/or chronic respiratory conditions) and becomes significantly and progressively higher after 50 years of age ${ }^{46}$ although the severe form of the disease increases linearly at any age stage. ${ }^{5}$ 


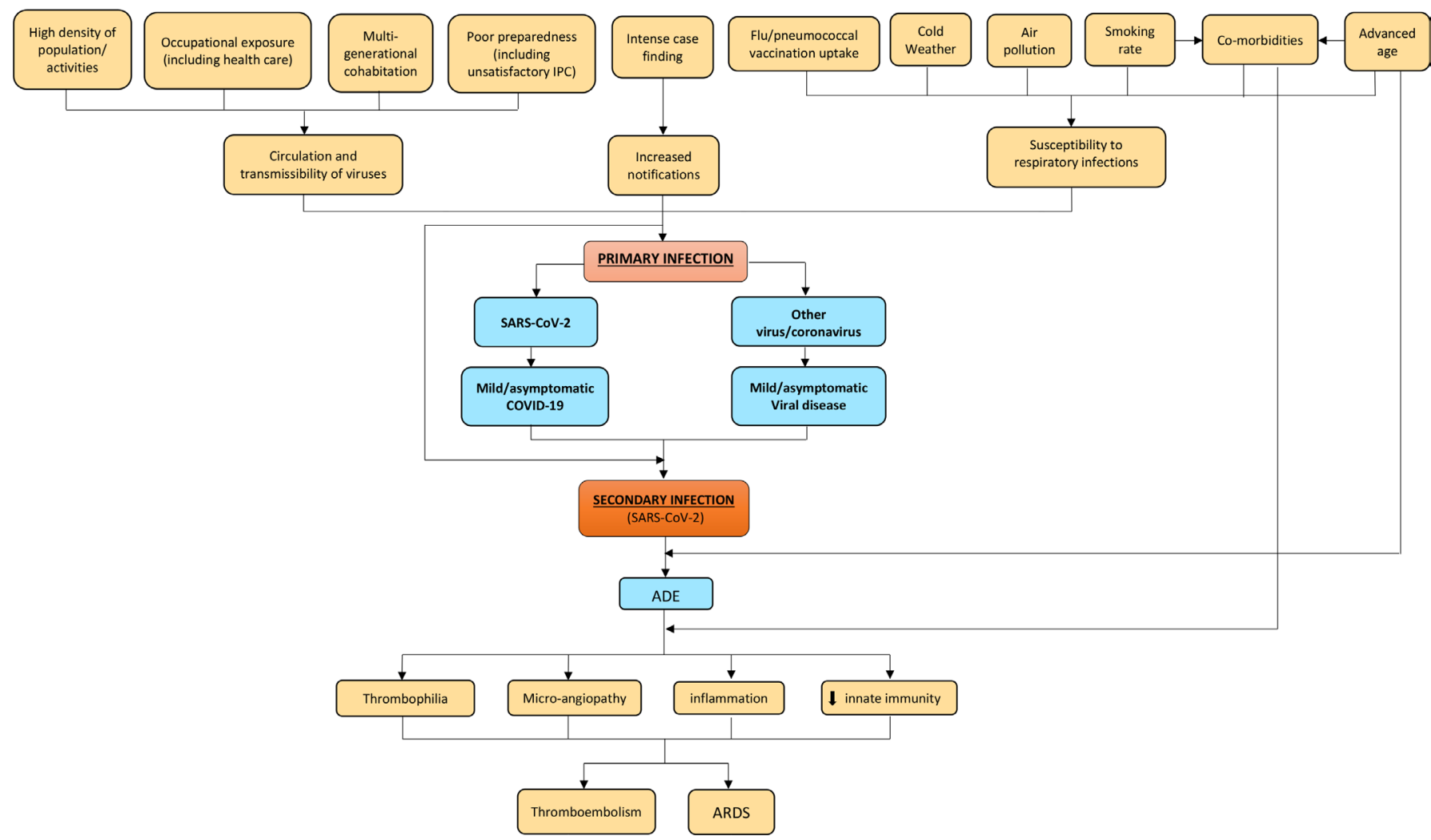

Figure 1 Conceptual framework explaining the relationships between various factors and incidence and severe/critical form of COVID-19. Established items: orange boxes; hypothetical items: blue boxes. ADE, antibody-dependent enhancement; ARDS, acute respiratory distress syndrome; COVID-19, coronavirus infectious disease 2019; IPC, infection prevention and control; SARS-CoV-2, severe acute respiratory syndrome coronavirus type.

Cold dry weather is a recognised risk factor for respiratory infections, rendering viruses as influenza more stable and individuals more susceptible. ${ }^{13} 14$ This applies also to SARS-CoV-2, the viability and transmissibility of which reportedly reduce with hot and humid weather conditions. ${ }^{14}$ Moreover, unfavourable disease progression and clinical outcomes of COVID-19 were found to be associated with cigarette smoking in a systematic review. ${ }^{15}$

A number of factors may have contributed to enhancing the risk of infection with SARS-CoV-2 in Northern Italy. The age by which half of all young people leave parental home is higher in Italy than other European Union countries, ${ }^{16}$ and such multigenerational cohabitation probably contributed to increase COVID-19 contagion among elderly individuals. The universal use of face masks was initially discouraged in Italy in order to preserve the limited supplies of personal protective equipment for professional use in healthcare settings; another argument initially was that face masks are ineffective in protecting against coronavirus infections. ${ }^{17}$ Further major findings of the relevant literature have been summarised in figure 1 . An extraordinary elevated incidence of COVID-19 could have been the result of a perfect storm triggered by multiple interplaying factors. The affected areas in Northern Italy (regions of Lombardy, Emilia-Romagna, Piedmont and Veneto) are characterised by high population density ${ }^{18}$ and recognised air pollution, ${ }^{190} 20$ especially from fine particulate matter (PM2.5), which was found to increase the risk of death from COVID-19 in the USA. ${ }^{21}$ Northern Italy includes several cities which, similarly to Philadelphia (USA) during the Spanish flu pandemic in $1918,{ }^{22}$ are historically important and densely populated, where social gatherings as well as business activities are certainly fundamental-the latter being vital to the economy of the entire country. These cultural and social dynamics might have influenced the initial resistance and reluctance of the general population to comply with the social restrictions progressively enforced by the Italian government (until full lockdown was established on 21 March). Moreover, the intense case finding in Italy was preceded by an initial overall underestimation of the COVID-19 threat by the Italian government and subsequently by the general population, who perceived the disease as just some sort of influenza, despite worrying news from the first affected country (China) ${ }^{23}$ Thereafter SARS-CoV-2 was also going to spread to other European countries, which have also now been heavily affected by the disease. ${ }^{1}$

The epidemiological investigations conducted by the Italian National Institute of Health (Istituto Superiore di Sanità) suggest that the vast majority of cases but the first three acquired the infection in Italy. It can therefore be reasonably argued that SARS-CoV-2 had been circulating in the country-especially in Lombardy, Emilia-Romagna, Piedmont and Veneto regions-for weeks before the first patient was found. ${ }^{24}$ Human 
coronaviruses are known to cause respiratory reinfections regardless of pre-existing humoural immunity, both at the individual and community level. ${ }^{25}$ At the same time, presumed hospital-associated transmission of SARS-CoV-2 has been reported since the initial stages of the COVID-19 outbreak in Wuhan (China) in $41 \%$ of the total number of patients, $70 \%$ of whom were healthcare staff. ${ }^{26}$ This could have also occurred in Italy, where healthcare workers reportedly make up $9 \%$ out of all COVID-19 cases. ${ }^{27}$ We therefore hypothesise (see blue boxes in figure 1) that repeated cycles of infection within a community (especially in older adults)—or even more worryingly in a healthcare setting-could have the potential to cause more severe forms of COVID-19, with acute respiratory distress syndrome (ARDS), the fundamental pathophysiology of severe viral pneumonia due to COVID-19, requiring admission to ICU. ${ }^{28}$ ARDS associated with COVID-19 shares clinical features with the critical form of the 2003 severe acute respiratory syndrome coronavirus (SARS-CoV) epidemic, in particular lymphopaenia, massive infiltration of phagocytes and inflammation sustained by cytokines. ${ }^{489}$

A plausible mechanistic hypothesis could be the antibody-dependent enhancement (ADE), sustained by prior exposure to SARS-CoV-2 or other viruses/coronaviruses. ${ }^{8}$ Previous circulation and exposure to other coronaviruses similar to SARS-CoV-2 causing mild/ asymptomatic cold-like symptoms shall in fact not be ruled out. ${ }^{8}$ Binding and neutralising antibody response against other types of human coronaviruses was recently reported to increase with age in adult patients, ${ }^{25}$ and this may explain the increased linear risk of severe COVID-19 with age, with death being significantly higher in patients older than $50 .^{5}$

Non-neutralising, subneutralising or even fully neutralising antibodies may play a key role in $\mathrm{ADE} .{ }^{30}$ Wan $e t a P^{30}$ have recently described a molecular mechanism for ADE involving the Middle East respiratory syndrome coronavirus (MERS-CoV), similar to what is already known for SARS-CoV and flaviviruses as Dengue and the West Nile virus. ${ }^{31-35}$ While the entry of SARS-CoV into the phagocytes occurred principally through the human ACE2 receptor, the $\mathrm{ADE}$ mechanism was shown to be enhanced by antibodies specific for the spike (S) envelope glycoprotein binding with the macrophage receptor and subsequent enhancement of target cell infections. ${ }^{33-35}$ Likewise, the antibody/opsonised SARS-CoV-2 particles may bind avidly with the IgFc receptors of target cells, increasing the virus yield as well as the production of cytokines. This may also explain the higher risk of thromboembolism reportedly associated with severe/critical COVID-19. ${ }^{46} 37$

Anecdotal clinical reports of 'biphasic infection' and 'cytokine storm' seem to possibly point towards this direction, biphasic infection simply being the immunological result of a secondary infection by other coronaviruses or a reinfection due to SARS-CoV-2. ${ }^{38-41} \mathrm{An}$ early elevation of serum proinflammatory cytokines, suggesting a pathological mechanism mediated by cytokine storm, has been observed with both severe forms of SARS-CoV and MERS-CoV infections. The latter two viruses share a genomic similarity of about $79 \%$ and 50\% with SARS-CoV-2, respectively. ${ }^{41}{ }^{42}$ Several Rhinolophus bats-related coronavirus strains have been found to share even higher sequence homology with SARS-CoV-2. ${ }^{33}$ An abnormal humoural response due to ADE, in the early stages of a secondary infection by SARS-CoV-2, may delay the innate antiviral immune response relying on the production of type 1 interferon (IFN-1). This would compromise the initial antiviral response of the host, with subsequent elevated influx of proinflammatory cytokines, hyperinflammatory neutrophils and monocytes-macrophages and hypercoagulable state accountable for ARDS and typical pneumonia observed in patients affected by severe/critical COVID-19 (figure 1). ${ }^{41} 4344$

If confirmed, this hypothesis would have relevant implications for the treatment of COVID-19 and the development of an effective vaccine. The licensing of a vaccine against human coronaviruses has failed thus far, partly because immunised individuals could potentially be at higher risk of ADE sustained by facilitated uptake of viral antigen-antibody complexes by target cells. ${ }^{413344}$ The approval of a vaccine against SARS-CoV-2 may encounter similar obstacles. Likewise, herd immunity would not be a possibility with COVID-19. WHO recommends passive immunotherapy when vaccine and antivirals are not available for emerging infections. ${ }^{45}$ In a preliminary uncontrolled case study on five critically ill patients with COVID-19 who developed ARDS, the administration of convalescent plasma-drawn from five patients who recovered from COVID-19 and containing SARS-CoV-2specific neutralising antibodies (IgG) - between 10 and 22 days since admission significantly improved the clinical status of all, resolving ARDS in four of them within 12 days since transfusion. ${ }^{46}$ On the other hand, the treatment of severe COVID-19 may also benefit from monoclonal antibodies targeting proinflammatory cytokines ${ }^{4}$ as well as supplements of IFN-1 in combination with other antiviral drugs. ${ }^{47-50}$

Whether secondary infections from other coronaviruses or repeated community reinfections of SARS-CoV-2 may account for more severe presentations of COVID-19 observed in some countries compared with others, ${ }^{8}$ and whether it is only a matter of time for the virus to circulate and infect a significant proportion of the population before causing reinfections and therefore more severe clinical features, are something which will require more indepth epidemiological and immunological/serological investigations. A better understanding of any underlying immunological mechanism or any additional risk factor which could explain cross-country differences in the rates of severe disease and mortality attributable to COVID-19 will help to guide international public health responses during this ongoing pandemic. It will be important to clarify if the ARDS mechanism responsible for the severe 
respiratory infection could potentially be attributable to ADE.

Two different in vivo strategies could be employed to endorse this hypothesis.

First (observational design), all healthcare workers and blood donors should undergo serum test for COVID-19. Individuals presenting SARS-CoV-2 IgG antibodies should be included in a local/regional/national ad-hoc register and monitored over time for the possible development of severe disease sustained by ADE, which would need to be confirmed by blood count, dosage of IFN and proinflammatory cytokines, in addition to chest CT scan. The risk of developing severe COVID-19 should be estimated and stratified by relevant risk factors, including baseline serum level of SARS-CoV-2-specific IgG antibodies, age, sex, potential occupational exposure, medical history (particularly previous infections and vaccination status), any comorbidities, area of residence and health status of household members, among others.

Second (experimental laboratory design), animal models (hamsters, rodents, palm civets, monkeys, ferrets) ${ }^{3351} 52$ could be infected by SARS-CoV-2 (or other viruses/coronaviruses) and subsequently re-exposed to SARS-CoV-2 to verify the possibility of onset of ARDS sustained by ADE.

Contributors LC, JP, SB, GP and GM equally contributed to conceiving the idea and drafting the manuscript. SC and GS contributed to drafting the manuscript.

Funding The authors have not declared a specific grant for this research from any funding agency in the public, commercial or not-for-profit sectors.

Competing interests None declared.

Patient consent for publication Not required.

Provenance and peer review Not commissioned; externally peer reviewed.

Data availability statement There are no data in this work.

Open access This is an open access article distributed in accordance with the Creative Commons Attribution Non Commercial (CC BY-NC 4.0) license, which permits others to distribute, remix, adapt, build upon this work non-commercially, and license their derivative works on different terms, provided the original work is properly cited, appropriate credit is given, any changes made indicated, and the use is non-commercial. See: http://creativecommons.org/licenses/by-nc/4.0/.

ORCID iD

Luca Cegolon http://orcid.org/0000-0002-6285-7355

\section{REFERENCES}

1 Worldometers. Coronavirus COVID-19 outbreak, 2020. Available: https://www.worldometers.info/coronavirus/ [Accessed 17 Apr 2020].

2 World Health Organization. Report of the WHO-China joint mission on coronavirus disease 2019 (COVID-19), 2020. Available: https:// www.who.int/ publications-detail/report-of-the-who-china-jointmission-oncoronavirus- disease-2019-(covid-19) [Accessed $17 \mathrm{Apr}$ 2020].

3 Chan JF-W, Yuan S, Kok K-H, et al. A familial cluster of pneumonia associated with the 2019 novel coronavirus indicating personto-person transmission: a study of a family cluster. Lancet 2020;395:514-23.

4 Cao X. COVID-19: immunopathology and its implications for therapy. Nat Rev Immunol 2020;20:269-70.

5 Verity R, Okell LC, Dorigatti I, et al. Estimates of the severity of coronavirus disease 2019: a model-based analysis. Lancet Infect Dis 2020;3099:30243-7.
6 China CDC. Vital Surveillances: the epidemiological characteristics of an outbreak of 2019 novel coronavirus diseases (COVID-19) China, 2020. China CDC - Weekly 2020;2:113-22.

7 Fisher D, Heymann D. Q\&A: The novel coronavirus outbreak causing COVID-19. BMC Med 2020;18:57.

8 Tetro JA. Is COVID- 19 receiving ade from other coronaviruses? Microbes Infect 2020;22:72-3.

9 Index Mundi. Japan demographics profile, 2019. Available: https:// www.indexmundi.com/japan/demographics_profile.html [Accessed 3 Apr 2020].

10 Index Mundi. Italy demographic profile, 2019. Available: https:// www.indexmundi.com/italy/demographics_profile.html [Accessed 3 Apr 2020].

11 Index Mundi. Germany demographics profile, 2019. Available: https://www.indexmundi.com/germany/demographics_profile.html [Accessed 3 Apr 2020].

12 Index Mundi. Iran demographics profile, 2019. Available: https:// www.indexmundi.com/iran/demographics_profile.html [Accessed 3 Apr 2020].

13 Wang J, Tang K, Feng K, et al. High temperature and high humidity reduce the transmission of COVID-19. SSRN., 2020. Available: http://dx.doi.org/10.2139/ssrn.3551767 [Accessed 18 Apr 2020].

14 Eccles R. An explanation for the seasonality of acute upper respiratory tract viral infections. Acta Otolaryngol 2002;122:183-91.

15 Vardavas Cl, Nikitara K. COVID-19 and smoking: a systematic review of the evidence. Tob Induc Dis 2020;18:20.

16 lacovou M, Skew A. Household structure in the EU. Available: https://www.econstor.eu/bitstream/10419/65910/1/632257644.pdf

17 Feng S, Shen C, Xia N, et al. Rational use of face masks in the COVID-19 pandemic. Lancet Respir Med 2020:pii: S22132600(20)30134-X.

18 Office for National Statistics (ISTAT). Demography in figures. Available: Demo.istat.it/pop2019/index e html [Accessed 3 Mar 2020].

19 Bigi A, Ghermandi G, Harrison RM. Analysis of the air pollution climate at a background site in the PO Valley. J Environ Monitor 2012;14:552-63.

20 Xia X, Zhang A, Liang S, et al. The association between air pollution and population health risk for respiratory infection: a case study of Shenzhen, China. Int J Environ Res Public Health 2017;14:950.

21 Wu X, Nethery RC, Sabath BM, et al. Exposure to air pollution and COVID-19 mortality in the United States. MedRxiv 2020.

22 Hannigan T, Wang MS, Steele C, et al. A cultural network approach for amending Covid-19 policy. Available: https://ssrn.com/abstract= 3566053 [Accessed 31 Mar 2020].

23 Start Magazine. Tutte Le capriole comunicative sul coronavirus. IL Comment di Punzi, 2020. Available: http://www.startmag.it/mondo/ tutte-le-capriole-comunicative-sul-coronavirus-il-commento-dipunzi/ [Accessed 3 Mar 2020].

24 National Institute of Health (ISS). Epicentro - Epidemia COVID-19, 2020. Available: https://www.epicentro.iss.it/coronavirus/bollettino/ Bollettino-sorveglianza-integrata-COVID-19_09-marzo-2020.pdf [Accessed 3 Mar 2020].

25 Gorse GJ, Donovan MM, Patel GB. Antibodies to coronaviruses are higher in older compared with younger adults and binding antibodies are more sensitive than neutralizing antibodies in identifying coronavirus-associated illnesses. J Med Virol 2020;92:1-6.

26 Wang D, Hu B, Hu C, et al. Clinical characteristics of 138 hospitalized patients with 2019 novel coronavirus-infected pneumonia in Wuhan, China. JAMA 2020;323:1061-9.

27 International Council of Nurses. High proportion of healthcare workers with COVID-19 in Italy is a Stark warning to the world: protecting nurses and their colleagues must be the number one priority, 2020. Available: https://www.icn.ch/news/high-proportionhealthcare-workers-covid-19-italy-stark-warning-world-protectingnurses-and [Accessed 17 Apr 2020].

28 Yang X, Yu Y, Xu J, et al. Clinical course and outcomes of critically ill patients with SARS-CoV-2 pneumonia in Wuhan, China: a singlecentered, retrospective, observational study. Lancet Respir Med 2020;8:475-81.

29 Cheung CY, Poon LLM, Ng IHY, et al. Cytokine responses in severe acute respiratory syndrome coronavirus-infected macrophages in vitro: possible relevance to pathogenesis. J Virol 2005;79:7819-26.

30 Wan Y, Shang J, Sun S, et al. Molecular mechanism for antibody-dependent enhancement of coronavirus entry. J Virol 2020;94:e02015-19.

31 Gollins SW, Porterfield JS. Flavivirus infection enhancement in macrophages: radioactive and biological studies on the effect of antibody on viral fate. J Gen Virol 1984;65 (Pt 8):1261-72.

32 Wang W-H, Urbina AN, Chang MR, et al. Dengue hemorrhagic fever - a systemic literature review of current perspectives on 
pathogenesis, prevention and control. J Microbiol Immunol Infect 2020.

33 Yang Z-yong, Werner HC, Kong W-pui, et al. Evasion of antibody neutralization in emerging severe acute respiratory syndrome coronaviruses. Proc Natl Acad Sci U S A 2005;102:797e801.

34 Wang S-F, Tseng S-P, Yen C-H, et al. Antibody-Dependent SARS coronavirus infection is mediated by antibodies against spike proteins. Biochem Biophys Res Commun 2014;451:208-14.

35 Tirado SMC, Yoon K-J. Antibody-Dependent enhancement of virus infection and disease. Viral Immunol 2003;16:69-86.

36 JF X, Wang L, Zhao L, et al. Risk assessment of venous thromboembolism and bleeding in COVID-19 patients. Research Square. In Press 2020.

37 Levi M, Thachil J, Iba T, et al. Coagulation abnormalities and thrombosis in patients with COVID-19. Lancet Haematol 2020. doi:10.1016/S2352-3026(20)30145-9. [Epub ahead of print: 11 May 2020].

38 Mehta P, McAuley DF, Brown M, et al. COVID-19: consider cytokine storm syndromes and immunosuppression. Lancet 2020;395:1033-4.

39 Mahallawi WH, Khabour OF, Zhang Q, et al. Mers-Cov infection in humans is associated with a pro-inflammatory Th1 and Th17 cytokine profile. Cytokine 2018;104:8-13.

40 Wong CK, Lam CWK, Wu AKL, et al. Plasma inflammatory cytokines and chemokines in severe acute respiratory syndrome. Clin Exp Immunol 2004;136:95-103.

41 Prompetchara E, Ketloy C, Palaga T. Immune responses in COVID-19 and potential vaccines: lessons learned from SARS and MERS epidemic. Asian Pac J Allergy Immunol 2020;38:1-9.

42 Lu R, Zhao X, Li J, et al. Genomic characterisation and epidemiology of 2019 novel coronavirus: implications for virus origins and receptor binding. Lancet 2020;395:565-74.
43 Pedersen SF, Ho Y-C. SARS-CoV-2: a storm is raging. J Clin Invest 2020;130-2202-5.

44 Olsen CW, Corapi WV, Ngichabe CK, et al. Monoclonal antibodies to the spike protein of feline infectious peritonitis virus mediate antibody-dependent enhancement of infection of feline macrophages. J Virol 1992;66:956-65.

45 Zhang L, Liu Y. Potential interventions for novel coronavirus in China: a systematic review. J Med Virol 2020;92:479-90.

46 Shen C, Wang Z, Zhao F, et al. Treatment of 5 critically ill patients with COVID-19 with convalescent plasma. JAMA 2020;323:1582

47 Sallard E, Lescure F-X, Yazdanpanah Y, et al. Type 1 interferons as a potential treatment against COVID-19. Antiviral Res 2020;178:104791.

48 Gao L, Yu S, Chen Q, et al. A randomized controlled trial of lowdose recombinant human interferons alpha- $2 b$ nasal spray to prevent acute viral respiratory infections in military recruits. Vaccine 2010;28:4445-51.

49 Loutfy MR, Blatt LM, Siminovitch KA, et al. Interferon alfacon-1 plus corticosteroids in severe acute respiratory syndrome: a preliminary study. JAMA 2003;290:3222-8.

50 Omrani AS, Saad MM, Baig K, et al. Ribavirin and interferon alfa-2a for severe middle East respiratory syndrome coronavirus infection: a retrospective cohort study. Lancet Infect Dis 2014;14:1090-5.

51 Jaume M, Yip MS, Cheung CY, et al. Anti-Severe acute respiratory syndrome coronavirus spike antibodies trigger infection of human immune cells via a $\mathrm{pH}$ - and cysteine protease-independent Fc $\gamma \mathrm{R}$ pathway. J Virol 2011;85:10582-97.

52 Kam YW, Kien F, Roberts A, et al. Antibodies against trimeric S glycoprotein protect hamsters against SARS-CoV challenge despite their capacity to mediate FcgammaRII-dependent entry into B cells in vitro. Vaccine $2007 ; 25: 729-40$ 